\title{
A Data Driven Approach to Identify the Contributing Factors of Traffic Death in Low, Middle, and High- Income Countries
}

\author{
Nouri Gsouda, Xiaohui Zhong and Utpal Dutta* \\ Civil, Architectural \& Environmental Engineering, University of Detroit Mercy, USA
}

*Corresponding author: Utpal Dutta, Civil, Architectural \& Environmental

Engineering, University of Detroit Mercy, USA.

Received Date: April 24, 2020

Published Date: May 29, 2020

\begin{abstract}
Road traffic crashes have been and will continue to be one of the primary causes of mortality all over the world. Globally, road traffic crashes have a widespread and devastating effect on public health and the global economy. According to The World Health Organization (WHO) [1], it is estimated that there are around 1.24 million people who die worldwide from traffic crashes. It is imperative to find out what factors contribute to the Traffic Death Rate (TDR).

This paper presents the finding of a study that used a data driven approach to identify the contributing factors of TDR in three groups of countries (low, medium, high) according to Gross National Income (GNI) per capita defined by WHO. By Traffic Death Rate (TDR), we define it as Number of Traffic/Number of Registered Vehicles.
\end{abstract}

This study intends to address the following research questions:

- Do TDRs have different patterns among the countries in three level of GNI?

- If yes, what are the main factors impacts to the TDRs positively or negatively? At what degree?

Based on the finding, recommendations aiming different types of countries will be made to make campaign to reduce TDR.

\section{Data collection and Analysis}

Three years of (2007, 2010 and 2013) traffic death related data along with GNI of each country are collected. The data sources include the WHO [1] and its partners; The World Bank, the United Nation (UN), and other international organizations. Data elements consist of number of road traffic deaths, total population, total area, urban population, alcohol consumption, number of registered vehicles, Education Index, Human Development Index, and GNI. Analysis variables are derived from these elements. KolmogorovSmirnov test and t-test show that the distributions of the TDR are significantly different among the three groups of countries with different means. Thus all related variables are standardized, and stepwise linear regression analysis was conducted within each group of countries using TDR as the dependent variable. The independent variables include: Registered Vehicles / Population, Registered Vehicles / Proportion of Urban population, Income, Education Index, Human Development Index, Population Density,
Proportion of Urban population, Social Globalization, Cultural Globalization, Alcohol Consumption, Average Drivers Ages.

The regressions produce three distinct models presented in Table 1.

These models show the following results which will be discussed and interpreted in detail in the full paper:

- $\quad$ Proportion of Urban Population is the only significant factor common to all three types countries. It can be interpreted as the higher the Proportion of Urban Population, the lower the TDR and its effect is more significant in the low income countries.

- $\quad$ Vehicles/Population has been identified a factor increasing the TDR in case of low and medium income countries, with more severe in the low income countries. 
- $\quad$ Population Density and Average Drivers Age are factors negatively associated with TDR in the medium and high income countries both with lighter effect in high income countries.

- Alcohol Consumption contributes to TDR in low and medium income countries.
- Human Development Index has displayed conflicting influence between medium and low income countries.

- Social Globalization Index is a negatively impacted factor in medium income countries.

Table 1: Results of Statistical Analysis.

\begin{tabular}{|c|c|c|c|c|c|c|c|}
\hline \multirow[b]{2}{*}{ Variables } & \multirow[b]{2}{*}{ Unit } & \multicolumn{2}{|c|}{ Low Income Countries } & \multicolumn{2}{|c|}{ Middle Income Countries } & \multicolumn{2}{|c|}{ High Income Countries } \\
\hline & & Mean & $\begin{array}{c}\text { Regression } \\
\text { coefficient of } \\
\text { significant variables }\end{array}$ & Mean & $\begin{array}{c}\text { Regression } \\
\text { coefficient of } \\
\text { significant variables }\end{array}$ & Mean & $\begin{array}{c}\text { Regression coefficient } \\
\text { of significant } \\
\text { variables }\end{array}$ \\
\hline $\begin{array}{c}\text { Death/Registered } \\
\text { Vehicles }\end{array}$ & $\begin{array}{c}\text { Death } / 10,000 \\
\text { Registered Vehicles }\end{array}$ & 32.1 & & 13.7 & & 1.67 & \\
\hline $\begin{array}{l}\text { Vehicles/ } \\
\text { Population }\end{array}$ & $\begin{array}{l}\text { Vehicles / 10,000 } \\
\text { Population }\end{array}$ & 360 & 3.643 & 2,080 & 0.552 & 6,100 & \\
\hline $\begin{array}{l}\text { Human } \\
\text { Development } \\
\text { Index }\end{array}$ & $(0-1)^{*}$ & 0.48 & & 0.7 & 0.818 & 0.87 & -0.644 \\
\hline $\begin{array}{l}\text { Population } \\
\text { density }\end{array}$ & $\begin{array}{l}\text { people per sq. km of } \\
\text { land area }\end{array}$ & 187 & & 129 & -0.4 & 202 & -0.105 \\
\hline $\begin{array}{c}\text { Proportion of } \\
\text { Urban population }\end{array}$ & $\%$ & 27 & -1.662 & 58 & -0.875 & 78 & -0.202 \\
\hline $\begin{array}{c}\text { Social } \\
\text { Globalization }\end{array}$ & $(0-100)^{* *}$ & 47.04 & & 67.94 & -0.394 & 81.93 & \\
\hline $\begin{array}{c}\text { Alcohol } \\
\text { Consumption }\end{array}$ & Liter / Capita & 2.51 & 0.605 & 4.73 & 0.251 & 9.05 & \\
\hline $\begin{array}{c}\text { Average of Drivers } \\
\text { Ages }\end{array}$ & Year & 36.2 & & 40.21 & -0.736 & 45.21 & -0.17 \\
\hline
\end{tabular}

\section{Conclusion}

This paper identified a set of factors that influenced traffic death in countries with different level of GNI. Some factors are common between and among countries. Most cases common variables follow similar trends other than one with conflicting trends. Based on these results, we can come up with different recommendations for different groups of countries to control the TDR. For future study, a clustering analysis will be performed to classify the counties based on more comprehensive scenario and then significant factor will be identified.

\section{Acknowledgement}

No.

\section{Conflict of Interest}

No conflict of interest.

\section{References}

1. World Health Organization (2017) Road traffic injuries. 